\title{
From conditioning to learning communities: implications of fifty years of research in e-learning interaction design
}

\author{
Andrew Ravenscroft \\ London Metropolitan University \\ email: aravenscroft@londonmetac.uk
}

\begin{abstract}
This paper will consider e-learning in terms of the underlying learning processes and interactions that are stimulated, supported or favoured by new media and the contexts or communities in which it is used. We will review and critique a selection of research and development from the past fifty years that has linked pedagogical and learning theory to the design of innovative e-learning systems and activities, and discuss their implications. It will include approaches that are, essentially, behaviourist (Skinner and Gagné), cognitivist (Pask, Piaget and Papert), situated (Lave, Wenger and Seely-Brown), socioconstructivist (Vygotsky), socio-cultural (Nardi and Engestrom) and community-based (Wenger and Preece). Emerging from this review is the argument that effective elearning usually requires, or involves, high-quality educational discourse, that leads to, at the least, improved knowledge, and at the best, conceptual development and improved understanding. To achieve this I argue that we need to adopt a more holistic approach to design that synthesizes features of the included approaches, leading to a framework that emphasizes the relationships between cognitive changes, dialogue processes and the communities, or contexts for e-learning.
\end{abstract}

\section{Introduction}

Most stakeholders at all levels of education expect that innovative, improved and more highly communicative pedagogies will be realized through the exploitation of new educational media. But has research and development in this area truly delivered findings that support these anticipations? This paper will argue that it is useful to step back from institutional and practical concerns about Virtual Learning Environments (VLEs) and online courses, so that we can consider e-learning in terms of the underlying learning processes and interactions that are stimulated, supported or favoured by new media and the contexts or communities in which they are used. (Currently, the term 'e-learning' is used 
quite loosely in the literature to represent learning that is assisted, augmented or 'delivered' by technology. It is this typical and broad coverage of the term that is used in this article). We will review and critique a selection of research and development from the past fifty years that has linked pedagogical and learning theory to the design of innovative e-learning systems and activities and assess the implications for e-learning design. Each initiative will be dealt with concisely, and the most striking findings presented; see Ravenscroft (2001) for a more detailed and descriptive account of some of the included approaches. This review is necessarily selective and aimed at surfacing important work that is often overlooked, but which is valuable to contemporary researchers and practitioners. So the omission of accounts of some well referenced and relatively recent work, such as that of Laurillard (2002), Mayes (1993) and Duffy, Jonassen and Lowyck (1993), as well as those working in the area of Computer Supported Collaborative Learning (CSCL) (for example, Dillenbourg, 1999; McConnell, 2000; Kirschner, 2002) is not intended to prejudice their contribution to this field. Selections are made in order to refocus and elaborate the landscape of learning technology research and development from an interaction perspective.

\section{Learning as shaping behaviour: Skinner and Gagné}

Arguably, the genesis of e-learning dates back to the 1950s, when educational technology researchers applied behaviourist ideas to the development of 'teaching machines'. These implemented Skinner's (1954) notions of operant conditioning through reinforcement schedules in the context of programmed instruction. Skinner believed that behaviour was shaped by the reinforcing consequences delivered by the environment to responses, or operants, made by the student. Therefore, the emphasis was given to designing an external environment which shaped behaviour through learner-system interactions. Typically, information was presented in brief chunks, followed by questions and immediate feedback that reinforced correct responses. Therein lay the main problem with the approach. Although correct behaviour was reinforced, incorrect responses, and even minor errors, such as misspellings or correct semantic substitutions, could not be dealt with because no diagnostic, explanatory or remediatory strategies existed in such systems. Further, there was no opportunity for reflection and intervention on the part of the student that deviated from the prescribed learning tracks.

To provide structure to the curriculum elements making up a learning programme, Gagné (1974) proposed a methodology of task analysis that enhanced both conceptual and procedural knowledge under his proposed framework of intellectual skills. This enabled the 'conditions' of learning, for achieving the attainment objectives, to be engineered, since his analysis provided advice on both the sequencing and types of instructions required to meet differing objectives. However, it soon became apparent that the interactions in these learning programmes was also too limited and, in practice, the main focus was given to drill-and-practice. Although this scheme can be enhanced through applying Keller's (1983) motivational approach to learning, as specified by his ARCS (Attention, Relevance, Confidence, Satisfaction) model, this does not address its somewhat overly pre-structured nature.

Summing up, both these initiatives were essentially, too prescriptive and pre-structured on the part of the instructional designers. Cognitive constructivists in line with Piaget 
(1971, 1973) and social constructivists following Vygotsky (1974), who are discussed later, would emphasize that this meant that little initiative was given to the students, who had no opportunity for experimentation, dialogue, reflection and 'higher level' conceptual thinking and reasoning. Learners are not tabula rasa and they are all different. So the knowledge and processes they bring to an educational interaction has a significant bearing on what and how they learn from these interchanges.

\section{Addressing individual differences: Pask and his colleagues}

About the same time as Gagné, more cognitively orientated, learner-centred approaches to e-learning design were also developed that addressed learner differences. Based on Piagetian-style experiments, the cyberneticist Pask and his colleague Scott (Pask and Scott, 1972) identified serial (step-by-step) and holist (global) learning styles, and developed the CASTE (Course Assembly System and Tutorial Environment) system to support both approaches. This gave students control over curriculum navigation and the types of material used in learning. In further experiments Pask and his colleagues constrained the system to support learning styles that mismatched the one identified for the learner and vice versa. He found that this mismatching produced inferior learning compared with trials that matched the learning style with the imposed interaction style. Although the concept of learning styles might be considered problematic, in that it cannot clearly predict consequences, it suggests quite strongly that students have preferred methods of interaction, that should be accommodated by e-learning approaches. Pask also suggested that, to exploit fully the serialist-holist dimension, conversational guidance needed to be introduced to ensure an appropriate mapping between learning styles and teaching strategy. This was because students may not be aware of their predominant learning style. Indeed, Pask viewed conversation as critical in both cybernetic and conventional teachinglearning contexts, stating:

To summarize the matter, teaching systems ought to be conversational in form and so devised that strategies are matched to individual competence. (Pask, 1975, p. 222)

A major contribution made by Pask and his colleagues was that, unlike the more behaviourist-inspired approaches to design (Skinner, 1954; Gagné, 1974), they allowed more learner control of the interaction and hence facilitated different learning styles, albeit within a prescribed knowledge-base. They took account of cognitive individual differences such as the serialist-holist distinction, whilst still guiding and structuring the interaction by placing constraints on the path through the curriculum materials, thus achieving a blend of learner freedom and tutoring guidance. Although Goodyear, Asensio, Jones, Hodgson and Steeples (2003) have recently suggested, in the context of an evaluation of online courses, that good design and management is positive for all types of students, Pask's work points out that any relative value for students should be considered and addressed $a$ priori, at the design stage. Pask also emphasized the role of dialogue, and the necessity for student and tutor to negotiate the most appropriate interaction style. Nevertheless there was arguably an epistemological drawback in this work, similar to that observed with more behaviourist approaches, since all the 'knowledge to be learned' had to be pre-specified. So, intensive knowledge engineering was required and there was no opportunity for the learner to explore, assimilate or create unanticipated knowledge and information. In brief, there were limited opportunities for more creative ideas and knowledge construction. 


\section{Cognitive constructivism: Piaget, Papert and the creation of individual meaning}

An emphasis on learner-centred and activity-orientated cognitive processes for knowledge assimilation, creation and construction are typical features of the constructivist paradigm, which has been developed by a number of researchers (such as Papert, 1980; Fosnot, 1996; Jonassen, Mayes and McAleese, 1993; see Duffy et al., 1993 for a review) who have been influenced by the work of Jean Piaget (1971, 1973). Probably the most engaging application of this theoretical stance within e-learning was delivered by Seymour Papert (1980) in his book Mindstorms and with the LOGO programming language that he developed. Although the work of Piaget and Papert was aimed at understanding and developing intellectual development in children, arguably their work carries broader significance, in that it focuses on processes and mechanisms - such as experimentation, reflection and abstraction - that are also prevalent and important in 'adult' learning.

According to Piaget, the child acts on the world, with expectations about consequent changes, and, when these are not met they enter into a state of cognitive conflict or disequilibrium. Thus, they seek to retain an equilibrium state and so accommodate unexpected data or experience into their understanding of the context under exploration. In a sense, the child is conceived as a scientist (Driver, 1983), setting hypotheses and testing them by actively interacting with the world.

Inspired by these constructivist ideas, Papert (1980) developed the LOGO language, which allowed learners to create and explore their own mental models and programmed microworlds and thus create individual meaning for themselves. As it was originally conceived, each child had 'their own machine', and LOGO was designed to prompt a purely learner-centred interaction in which the student 'told the computer what to do' and observed its response. It was a curriculum innovation, fostering 'learning by discovery', and allowing students to develop their own knowledge and understanding in a principled manner through devising their own curriculum of activities.

An important finding from the evaluation studies (Sutherland, 1983; Hoyles and Noss, 1992) was that teachers who had used LOGO were sceptical about the value of pure discovery learning, because they needed to support the interactions directly, through guided discussions, or indirectly by providing worksheets. So, it had to be grounded in authentic discursive activity. In defence of LOGO, Papert argued that most of the studies were flawed in their philosophy, measuring outcomes instead of examining the richness of the interactions and the learning process. But another critical question, considering the particularity of the language in relation to issues of transfer, remained unanswered. Was LOGO an effective cognitive tool supporting conceptual development and learning? Or, was it the case that students learned to think in a 'LOGO way' only about LOGO itself?

\section{Situated learning: participation in authentic practice}

The requirement for authentic learning in real situations, as compared with the relatively abstract and conceptual approach of LOGO, is a central tenet of situated learning (SeelyBrown, Collins and Daguid, 1989; Lave and Wenger, 1991). This stance is often considered antithetical to more cognitive approaches to learning such as those above. A position that is concisely proposed, in relation to new media technology, by Pea and Seely-Brown (1996): 
The situated nature of learning, remembering, and understanding is a central fact. It may appear obvious that human minds develop in social situations, and that they use tools and representational media that culture provides to support, extend, and reorganize mental functioning. But cognitive theories of knowledge representation and educational practice, in school and in the workplace, have not been sufficiently responsive to questions about these relationships. And the need for responsiveness has become salient as computational media radically reshape frontiers of individual and social action, and as educational achievement fails to translate into effective use of knowledge ... In changing situations of knowledge acquisition and use, the new interactive technologies redefine - in ways yet to be determined - what it means to know and understand, and what it means to become 'literate' or an 'educated citizen'. (Pea and Seely Brown, 1996, p. vii)

So this approach encourages us to 'explore learning as legitimate peripheral participation' (Lave and Wenger, 1991, p. 34) in authentic activity rather than conceive it as an ostensibly knowledge-based, and often abstract, process.

Whilst providing an incisive argument for turning our attention to the local, social and socio-cultural dimensions of learning, the approach surfaces some difficulties for elearning design, because it is essentially analytic rather than predictive (see also Wenger's (1998) work on Communities of Practice discussed later). A corollary of this, articulated in objections proposed by Anderson, Reder and Simon (1996) is that situated approaches are too specific and authenticity-focused. They do not allow us to consider issues of transfer or the common necessity for independent training in sub-components of complex social activity (for example, independently practising your part in the orchestra). Also, work with computer simulations has illustrated another significant criticism of Anderson et al. (1996), that learning often requires the interplay of abstract reasoning and concrete, experiential activity. It does not have to be one or the other.

Although 'hard' situationists may possibly question whether computer simulations are truly representative of this approach, as they predispose transfer to 'real' situations, most moderate researchers are less likely to be so extreme. It is generally accepted that notions such as 'experiential learning' and 'learning by doing' fostered by simulations map onto some of the central principles of situated learning (for example, see Laurillard, 1993, 2002), as interaction emphasizes authentic activity with analogues of real situations (for example, see Hartley, Ravenscroft and Williams, 1996). However, recent work has illustrated that simulations are more effective when both the description of the conceptions underpinning interaction with the system and reflection on the consequent output is guided and elaborated during a dialogue with a tutor (Hartley, 1998; Pilkington and Parker-Jones, 1996). Although some situationists would point out that this amounts to the learner 'drawing' resources from their immediate environment, it also emphasizes that in order to be truly powerful and effective, situated activity has to be integrated with more cognitive and conceptual activity, such as processes of reflection, abstraction and generalization. And these are typically stimulated, supported or favoured by high-quality instructional dialogue.

8 


\section{Social constructivism: instructional dialogue and intelligent tutoring systems}

The necessity for an instructional dialogue, of a 'scaffolding' nature, between the learner and a tutor, or more capable other, was the focus of Vygotsky's (1978) theory of the development of higher mental processes. His approach makes a substantial contribution by linking activity situated 'in the social' to higher-order thinking and reasoning. A central tenet of his account is that learning occurs through internalizing dialogical activity and its signification systems (such as languages) that occur in the social. So, for example he would argue that we develop critical reasoning skills through internalizing the process and content of dialogical argumentation.

This primacy of language in learning and the requirement to adapt interaction to individual learners was reflected in a number of intelligent tutoring systems (hereafter ITS) initiatives (for example, see Wenger, 1987) that modelled and maintained instructional dialogues. A number of early ITS aimed to teach the learner using a 'Socratic dialogue' derived from discourse analysis of human tutoring, in order to teach a subject and foster the acquisition of generic reasoning skills. SCHOLAR (Carbonell, 1970) and WHY (Collins, 1977) used the method to teach South American geography and causal reasoning respectively. However, although these systems had good semantic and syntactic natural language properties, they had limited or shallow strategic knowledge, which remained, to a large measure, unprincipled. Later work by Clancey (1987) on a system called GUIDON attempted to address this through a separation of domain and pedagogical knowledge, but the strategic knowledge that guided the dialogue was still too shallow. McCalla (1993) and Ravenscroft and Pilkington (2000) have emphasized that this is only part of the problem. They hold that pragmatic, or contextual dialogue features, such as the goals and relative roles of interlocutors, the strategies they adopt and the types of speech act they may perform (Searle, 1969), are neglected by much of this work, yet they have to be carefully considered in designing educational dialogue.

Some recent work (for example, Maudet and Moore, 2000; Ravenscroft and Pilkington, 2000 ) has started to reconcile this difficulty through focusing on pragmatic level dialogue features, such as the roles and goals of interlocutors, the types of speech act they may perform and rules for legitimate educational dialogue. Specifically, some of these approaches have integrated domain knowledge within a dialogue-game approach that specifies explicit dialogue strategies and tactics, with rules of initiative-taking and the transfer of commitment through the types of utterances that are made (Ravenscroft and Hartley, 1999; Ravenscroft, 2000). Ravenscroft (1997) developed a computer-based pedagogy and approach to interaction design called 'learning as knowledge refinement' that is based on a Vygotskian approach to dialogue and empirical studies of collaborative argumentation (Hartley, 1998). Through generalizing this approach to system development Ravenscroft and Pilkington (2000) proposed a methodology of 'investigation by design' (IBD) that is currently being used to develop a number of dialogical cognitive tools that emphasize dialectical interaction (for example, see Ravenscroft, 2002).

Empirical studies, under experimental conditions, have demonstrated the effectiveness of this dialogue game approach (Ravenscroft, 2000; Ravenscroft and Matheson, 2002). However, they have also highlighted the need to conceptualize the broader, socio-cultural 
contexts and communities in which dialogues occur if we want to foster and support these favoured types of discourse in more naturalistic settings.

\section{Activity theory: a socio-cultural approach}

Although Vygotsky's work is sometimes considered as socio-cultural, activity theory arguably provides a more rigorous account of relations between learners and their social and cultural context. It is a development of Vygotsky's (1978) work that provides a framework for learning and development which accepts that meaning arises and evolves during interactions that are influenced by the social relations within a community of practice. Or, 'you are what you do' (Nardi, 1996, p. 7) in a natural context that is influenced by history and culture. Hence, human practices are conceived as developmental processes 'with both individual and social levels interlinked at the same time' (Knutti, 1996, p. 25). It emphasizes relationships between interactions, processes and outcomes and the relevance of social conditions, such as a shared enterprise and the need for mutual engagement of conceptualizations. Therefore, the relevance of conceptual similarities and differences and changes and developments over time are taken into account in the design of mediatedlearning activities (for example, see Engestrom, 1987).

Isroff and Scanlon (2001) have recently assessed activity theory in the context of computer-supported collaborative learning (CSCL), and reconsidering some of their previous studies using this framework. They concluded that, as it stands, activity theory is more useful as a framework for describing and communicating findings, and less effective as a framework for uncovering 'further insights' into designing and interpreting collaborative learning activities. Similarly, although Baker, Hansen, Joiner and Traum (1999) have used it to analyse and examine different forms of grounding in collaborative learning, and Lewis (1997) has employed it in researching interdependent parameters in distributed communities, its value as a prescriptive design paradigm for e-learning remains open to question.

Nevertheless, this and other research (Tolmie and Boyle, 2000) has demonstrated that an activity theory framework does hold some genuine value in shifting our attention to the relevance of social, cultural and historical influences and relationships that are implicated when we introduce and use innovative educational technologies. It also highlights the complexities associated with the way a design is operationalized within a context as its use develops over time, and has pointed out some of the limitations in theory that need to be addressed. Specifically, this approach has forced us to focus on the necessity to conceptualize the relationship between dialogical activity and the learning communities in which it occurs.

\section{E-learning communities}

According to Preece (2000), 'The internet has given rise to a new community model of communication' (p. xii). Currently, however, there is little agreement on what this model actually is, how we can conceptualize it, or how it can be operationalized and exploited for educational purposes. Preece (2000) herself argues for Community-Centred Development (CCD), that accepts the sociology and social psychology of community development and maintenance, putting the 'community' firmly at the centre of the design process in the same 
way that Norman (1986) conceived the 'user' as central. Within this scheme she points out that we need to support the evolution of communities, design for usability and plan for sociability. This approach seems to hold that learning should be conceived as a social process, but raises a crucial question about whether we can actually build online communities that truly satisfy the necessary social conditions for effective, and often dialectical, discourse interactions. Or, putting this another way, can we be sufficiently social online to have meaningful conversations, discussions and arguments that lead to conceptual change and development?

The recent work of Wenger (1998) on 'Communities of Practice' (CoP) considers meaning, along with learning and identity, as important features in the educative process and holds that:

engagement in social practice is the fundamental process by which we learn and so become who we are. The primary unit of analysis is neither the individual or social institutions but rather the informal 'communities of practice' that people form as they pursue shared enterprises over time. (Wenger, 1998: introductory notes)

Central to this notion, inspired by Lave and Wenger's (1991) work on 'situated cognition' (discussed earlier), is that these communities have knowledge about practice embedded within them, and therefore learning occurs through legitimate entry and participation within the community. Or, 'Learning is a process that takes place within a participation framework, not an individual mind' (Lave and Wenger, 1991, p. 15). Wenger (1998) argues that effective $\mathrm{CoP}$ are characterized by mutual engagement, joint enterprise, shared repertoire and the negotiation of meaning in practice.

Whilst this approach, like situated cognition, provides a useful analytic framework, this descriptive emphasis means that it cannot be readily articulated for e-learning design, a point that is emphasized by Wenger (1988) himself. As e-learning designers we have to be more prescriptive and promote learning as well as describe it. The challenge is to stimulate and promote the engagement in social practice that in turn leads to the formation of an efficient CoP. There is also a problem mapping some of Wenger's features to desired discourse practices in educational contexts. Whilst we obviously want to promote and identify features such as mutual engagement, shared repertoire and negotiation of meaning, other aspects such as joint accountability, diversity and partiality are not necessarily appropriate in many educational contexts - except perhaps for informal learning. One reason why it is not yet clear how to design, develop and maintain a CoP supporting and engaging e-learning discourse is because in educational settings it is often unclear what the 'practice' actually is. In such contexts a greater emphasis is given to knowledge-based and conceptual activity rather than cooperative task-orientated activity. Finally, although Wenger's work has provided a valuable conceptual resource of sociocultural features that should be considered when designing, cultivating and developing communication in online communities I argue that the central tenet of this approach is too simplistic. When we consider the pedigree and support for more cognitive and sociocognitive approaches, such as those described, we cannot accept the claim that 'Learning is a process that takes place within a participation framework, not an individual mind' without significant qualification. Surely learning is a process that takes place within a participation framework and an individual mind. 


\section{Discussion and implications for e-learning research and development}

In considering the last fifty years in terms of the relationships between learning, or pedagogical theory, and interaction design, what can we conclude about designing e-learning in the twenty-first century? Two general points are highlighted by this review. First, research and development that clearly links theory to design has been piecemeal, but yet has delivered interesting and innovative educational systems and activities. However, in performing and evaluating these e-learning approaches, we have usually learned more about the learning process itself than about how to improve or optimize instruction. This is an interesting challenge for researchers, but can be discouraging for practitioners, and it must be admitted that, historically, the link between educational practice and learning theory has been weak. Perturbing the instructional process through introducing new learning technologies is bound to raise questions about 'what it actually takes to learn', though I argue that forcing the consideration of this issue is an invaluable contribution in itself. Second, these approaches to e-learning have developed in a somewhat dialectical manner, where typically new approaches have been adopted to address perceived shortcomings in existing ones. For example, the prescriptive, instructor-centredness of behaviourist approaches being superseded by more flexible, learner-centred constructivist approaches, that in turn had to accommodate social constructivist ideas - and an increasing current emphasis on online learning communities. This has lead to an increasing diversification and accumulation in approaches, with most of those cited still going strong in research and practice.

The key point here is that we have never really 'settled on' a predominant approach or theory, but instead the discipline has been characterized by a developing discourse and debate about the value of particular theories and the role of theory in general (for example, see Ravenscroft, 2001). I argue that familiarity with, and active participation in, this discourse, rather than favouring a particular theoretical stance, is the best way to inform and influence e-learning design. The implications of this point are particularly salient when we consider the main thrust of current operational developments and activities, which typically use generic VLEs that predispose rather narrow and didactic pedagogies which support a rather inflexible 'transmission' model of learning. These developments are undeniably driven by the available technology, which provides the sort of facilities (for example, online content, CMC, student management and tracking, online assessment, etc.) that integrate with existing practice rather than support innovation. This point was emphasized by leading UK researchers and practitioners in a recent Oxford Union debate on 'Beyond theory: educational best practice and the use of ICT for teaching and learning' (see http://www.oucs.ox.ac.uk/ltglevents/beyondnew/). Despite this history of relevant research, within most current institutional practice there is a paucity of innovative pedagogies that support more dialogical, dialectical and conceptual learning processes. This is the case even though a critique of previous work suggests that pedagogical approaches emphasizing these processes are both necessary and essential.

However, I argue that there is a productive way forward if we look to develop a more holistic and flexible approach from ongoing and previous research that builds upon lessons learned and findings across various initiatives. A key argument, that repeatedly emerges from this review - irrespective of theoretical orientation - is that effective e-learning usually requires or involves high-quality educational discourse that leads to - at the least - 
improved knowledge, and - at the best - conceptual development and improved understanding. And I hold that for this to be possible we need to adopt a more sophisticated approach to e-learning design that accounts for necessary relationships between cognitive changes, dialogue processes and the communities, or contexts, for learning. Or, putting this another way, we need a socio-cultural framework for cognitive change (Ravenscroft, 2002). This suggests an approach that does not necessarily favour one theory or approach against another, but instead distils from the debate features that can be transposed, applied or simply used to inform our current and prospective design activities. This may, in practice, require a blend of pedagogical approaches for addressing particular learning problems (see below). Although some learning theorists may object to such marriages, arguing that they may involve reconciling conflicting epistemologies, we must remember that our focus is on producing high-fidelity interaction designs. We are not focusing on investigating the psychology of learning in the first instance, although given that no theory of learning has yet become an oracle, we should consider this a desirable side effect.

\section{Towards e-learning discourse within a socio-cultural framework for cognitive change}

The framework proposed holds that learning should be redefined as the transformation and development of cognition, identities and communities. So we need to focus on how to develop thinking and reasoning in learners, support the social skills and presence to apply these cognitive skills and cultivate active participation in improving learning communities or communities of practice. This means that we need to approach design in terms of a synthesis of socio-cognitive and socio-cultural levels.

Thus far, work on developing educational dialogue models and system designs linked to cognitive change and development, that has been the focus for some investigators (see Ravenscroft and Pilkington, 2000, for a review), has been successful and necessitated at least ten years of research. So we now have a reasonable idea about what counts as patterns of good educational discourse, and how we can design systems that can effectively mediate favoured dialogue processes in ways that, hopefully, lead to the internalization of improved reasoning and dialectic processes. So a significant current challenge for e-learning is how to design or develop the social conditions and communities -in online or blended situations that give rise to, or accommodate, the dialogue models and discourse practices that are desired in e-learning contexts.

A next step must be to investigate and examine e-learning communities to develop a better conceptualization of how and why they operate successfully, paying particular attention to motivational, empathic and social issues. This should then provide the basis to either harmonize the operation of desired dialogue genres within existing community practice or, more prescriptively, to develop communities that are aimed at supporting high-quality collaborative e-learning discourse. We need to better conceptualize the way learners behave in e-learning communities with flexibility in the adoption of theory with respect to elearning. In considering a number of practical and ongoing initiatives Ravenscroft (2002) has highlighted the difficulty of cultivating and maintaining meaningful participation in online learning communities. I argue that some of these difficulties derive partly from a belief that there is a driving (cognitive) intellectualism that leads learners to participate meaningfully in educational discourses. But is this realistic, especially in less formal 
learning contexts? Wegerif (1998) has pointed out that participants need to move from 'outsiders to insiders' in relation to the community before they can actively participate and engage in meaningful discourses. One way to encourage this is by reconciling behaviouristic and social constructionist approaches, through considering the stimulation, motivation and reward for online behaviour as well as the need for educational discourse along Vygotskian lines. Additionally, in an ever expanding new media milieu we need to examine the 'invitational' features of online interaction, that could be affordances (Gibson, 1977) provided by the technology or the activities of the online community itself. One example of this approach is represented in the ongoing work of Ravenscroft, Hutchinson, Baur and Bradley (2003) who are integrating social learning theory (Bandura, 1977) within a socio-cultural approach to cultivating online communities, articulated in their MOCCA (Maxims for developing Online Communities and Communication using Affordances) framework. One way this is realized practically is through devising animateurs or Animator teams (A-teams) who demonstrate and stimulate types of online behaviour, acting as catalysts for interaction. We are planning and structuring exemplary interactions that 'invite people in' and get them simply participating in the first instance. As it is hoped that once learners begin to continue their participation and engage intellectually, they will be achieving sufficient cognitive reward and development to continue their active involvement without animation, and so the animateur or A-team can then 'fade out', allowing the community to grow in an organic way.

\section{Conclusions}

An overarching conclusion drawn from this review is that e-learning should be considered within a more holistic, socio-cultural framework for cognitive change, that synthesizes relevant features of more partisan approaches. Specifically, this means that we should focus on relationships between dialogue interactions and the cognitive changes that represent learning, and also conceptualize the contexts and communities that accommodate, favour or afford desirable discourse activity. This requirement for an informed theoretical flexibility and liberalism makes e-learning design a sophisticated endeavour. But given the lack of consensus about, and shortcomings of, initiatives that have adopted a more particular theoretical stance, whether it be predominantly behaviourist, cognitivist, situationist or whatever, I argue that this is a productive avenue for further research and development.

\section{Acknowledgements}

The author is especially grateful to Professor Roger Hartley of the University of Leeds for discussions and arguments about many included issues and commenting on this paper. Richard Joiner in the Department of Psychology at the University of Bath also made some useful comments. Also this paper has benefited significantly from the incisive comments and suggestions of the reviewers.

This project has been carried out with the support of the European Community in the framework of the Socrates Programme. The content of this project does not necessarily reflect the position of the European Community, nor does it involve any responsibility on the part of the European Community. 


\section{References}

Anderson, J. R., Reder, L. M., and Simon, H. A. (1996), 'Situated learning and education', Educational Researcher, 25, 5-11.

Baker, M., Hansen, T., Joiner, R. and Traum, D. (1999), 'The role of grounding in collaborative learning tasks', in P. Dillenbourg (ed.), Collaborative Learning: Computational and Cognitive Approaches, Amsterdam: Elsevier, 31-63.

Bandura, A. (1977), Social Learning Theory, Englewood Cliffs, NJ/London: Prentice Hall. Carbonell, J. (1970), 'AI in CAI: an artificial intelligence approach to computer-aided instruction', IEEE Transactions on Man-Machine Systems, 11, 190-202.

Clancey, W. J. (1987), Knowledge-based Tutoring: The GUIDON Program, Cambridge, MA: MIT Press.

Collins, A. (1977), 'Processes in acquiring knowledge', in R. C. Anderson, R. J. Spiro and M. E. Montague (eds), Schooling and the Acquisition of Knowledge, Hillsdale, NJ: Lawrence Erlbaum, 339-63.

Dillenbourg, P. (1999), Collaborative Learning: Cognitive and Computational Approaches, Oxford: Pergamon.

Driver, R. (1983), The Pupil as Scientist?, Milton.Keynes: Open University Press.

Duffy, T. M., Jonassen, D. H. and Lowyck, J. (eds) (1993), Designing Environments for Constructive Learning, Berlin: Springer.

Engestrom, Y. (1987), Learning by Expanding: An Activity Theory Approach to Developmental Research, Helsinki: Orienta-konsultit.

Fosnot, C. (1996), Constructivism: Theory, Perspectives and Practice, New York: Teachers College Press.

Gagné, R. M. (1974), Essentials of Learning and Instruction, Hinsdale, IL: Dryden Press.

Gibson, J. J. (1977), The Ecological Approach to Visual Perception, New York, NY: Houghton Mifflin.

Goodyear, P., Asensio, M., Jones, C., Hodgson, Y. and Steeples, C. (2003), 'Relationships between conceptions of learning, approaches to study and students' judgements about the value of their experiences of networked learning', $A L T-J, 11$ (1), 17-27.

Hartley, J. R. (1998), 'Qualitative reasoning and conceptual change: computer-based support in understanding science', in R. G. F. Winkels and B. Bredeweg (guest eds), Interactive Learning Environments: Special Issue on the Use of Qualitative Reasoning Techniques in Interactive Learning Environments, 5, 53-64.

Hartley, J. R., Ravenscroft, A. and Williams, R. J. (1992), 'CACTUS: command and control training using knowledge-based simulations', Interactive Learning International, 8 (2), 127-36.

Hoyles, C. and Noss, R. (1992), 'A pedagogy for mathematical microworlds', Educational Studies in Mathematics, 23, 31-57. 
Andrew Ravenscroft From conditioning to learning communities: fifty years of research in e-learning interaction design

Issroff, K. and Scanlon, E. (2001), 'Case studies revisited: what can Activity Theory offer?', Proceedings of International Conference on Computer Supported Collaborative Learning 2001 (CSCL 2001), Maastricht, Netherlands, 22-4 March 2001.

Jonassen, D. H., Mayes, T. and McAleese, R. (1993), 'A manifesto for a constructivist approach to technology in higher education', in T. M. Duffy, D. H. Jonassen and J. Lowyck (eds) (1993), Designing Environments for Constructive Learning, Berlin: Springer.

Keller, J. M. (1983), 'Motivational design of instruction', in C. M. Reigeluth (ed.), Instructional-Design Theories and Models, Hillsdale: NJ, Erlbaum.

Kirschner, P. A. (2002), 'Can we support CSCL? Educational, social and technological affordances for learning', in P. A. Kirschner (ed.), Three Worlds of CSCL: Can We Support CSCL?, Open Universitiet, Nederland.

Knutti, K. (1996), 'Activity theory as a potential framework for human-computer interaction research', in B. Nardi (ed.), Context and Consciousness: Activity Theory and Human-Computer Interaction, Cambridge, MA: MIT Press.

Laurillard, D. (1993), Rethinking University Teaching: A Framework for the Effective Use of Educational Technology (1st edn), London and New York: Routledge.

Laurillard, D. (2002), Rethinking University Teaching: A Framework for the Effective Use of Educational Technology (2nd edn), London and New York: Routledge.

Lave, J. and Wenger, E. (1991), Situated Learning: Legitimate Peripheral Participation, Cambridge: Cambridge University Press.

Lewis, R. (1997), 'An activity theory framework to explore distributed communities', Journal of Computer Assisted Learning, 13, 210-18.

Maudet, N. and Moore, D. J. (2000), 'Dialogue games as dialogue models for interacting with, and via, computers', Informal Logic.

Mayes, T. (1993), 'Impact of cognitive theory on the practice of courseware authoring', Journal of Computer Assisted Learning, 9, 222-8.

McCalla, G. I. (1993), 'Tutorial dialogue', Proceedings of International Conference on Computers in Education (ICCE), Taiwan, December 1993.

McConnell, D. (2000), Implementing Computer Supported Cooperative Learning, London: Kogan Page.

Nardi, B. (ed.) (1996), Context and Consciousness: Activity Theory and Human-Computer Interaction, Cambridge, MA: MIT Press.

Norman, D. A. (1986), 'Cognitive engineering', in D. Norman and S. Draper (eds) (1986), User-Centred Systems Design, Hillsdale, NJ: Erlbaum.

Papert, S. (1980), Mindstorms: Children, Computers and Powerful Ideas, New York: Basic Books.

Pask, G. (1975), The Cybernetics of Human Learning and Performance, London: Hutchinson. 
Pask, G. and Scott, B. C. E. (1972), 'Learning strategies and individual competence', International Journal of Man-Machine Studies, 4, 217-53.

Pea, R. and Seely-Brown, J. (1996), in S. Chaiklin and J. Lave (eds), Understanding Practice: Perspectives on Activity' in Context, Cambridge: Cambridge University Press, vii-viii.

Piaget, J. (1971), Structuralism, London: Routledge \& Kegan Paul.

Piaget, J. (1973), The Child's Conception of the World, London: Paladin.

Pilkington, R. M. and Parker-Jones, C: (1996), 'Interacting with computer-based simulation', Computers and Education, 3 (3), 275-85.

Preece, J. (2000), Online Communities: Designing Usability, Supporting Sociability, Chichester, UK: John Wiley \& Sons.

Ravenscroft, A. (1997), 'Learning as knowledge refinement: a computer-based approach', unpublished Ph.D. thesis, Computer based Learning Unit, University of Leeds, UK.

Ravenscroft, A. (2002), 'Communities, communication and cognitive change: social processes and designing engaging e-learning discourse', in N. Driscoll and T. C. Reeves (eds), Proceedings of E-Learn 2002, Association of the Advancement of Computing in Education (AACE), Norfolk, USA, 792-7.

Ravenscroft, A. (2001), 'Designing e-learning interactions in the 21st century: revisiting and rethinking the role of theory', European Journal of Education: Special Edition on Online Learning, 36 (2), 133-56.

Ravenscroft, A. (2000), 'Designing argumentation for conceptual development', Computers and Education, 34, 241-55.

Ravenscroft, A. and Hartley, J. R. (1999), 'Learning as knowledge refinement: designing a dialectical pedagogy for conceptual change', in S. Lajoie and M. Vivet (eds), Frontiers in Artificial Intelligence and Applications Volume 50. Artificial Intelligence in Education. Open Learning Environments: New' Computational Technologies to Support Learning, Exploration and Collaboration, Amsterdam: IOS Press, 155-62.

Ravenscroft, A., Hutchinson, A., Baur, E. and Bradley, C. (2003), 'MOCCA framework: maxims for developing online communities and communication using affordances', LTRI Technical Report, June 2003.

Ravenscroft, A. and Matheson, M. P. (2002), 'Developing and evaluating dialogue games for collaborative e-learning interaction', Journal of Computer Assisted Learning, 18 (1), 93-102.

Ravenscroft, A. and Pilkington, R. M. (2000), 'Investigation by design: developing dialogue models to support reasoning and conceptual change', International Journal of Artificial Intelligence in Education, 11, 273-98.

Searle, J. R. (1969), Speech Acts: An Essay in the Philosophy of Language, Cambridge: Cambridge University Press.

Seely-Brown, J., Collins, A. and Daguid, P. (1989), 'Situated cognition and the culture of learning', Educational Researcher, 18 (1), 32-42. 
Skinner, B. F. (1954), 'The science of learning and the art of teaching', Harvard Educational Review, 88-97.

Sutherland, R. (1983), 'Connecting theory and practice: results from the teaching of LOGO', Educational Studies in Mathematics, 24, 95-113.

Tolmie, A. and Boyle, J. (2000), 'Factors influencing the success of computer mediated communication (CMC) environments in university teaching: a review and case study', Computers and Education, 34, 119-40.

Vygotsky, L. (1978), Mind in Society, Cambridge, MA: Harvard University Press.

Wegerif, R. (1998), 'The social dimension of asynchronous learning environments', Journal of Asynchronous Learning Networks, 2 (1), 34-49.

Wenger, E. (1987), Artificial Intelligence and Tutoring Systems: Computational and Cognitive Approaches to the Communication of Knowledge, Los Altos, CA: Morgan Kaufman.

Wenger, E. (1998), Communities of Practice, Cambridge: Cambridge University Press. 